\title{
Research on Family Violence in Greater China: Opportunities, Challenges, and Development
}

\author{
Shih-Ya Kuo ${ }^{1} \cdot$ Hongwei Zhang ${ }^{2} \cdot$ Ruohui Zhao $^{1}$ \\ Published online: 15 June 2021 \\ (c) The Author(s), under exclusive licence to Springer Science+Business Media, LLC, part of Springer Nature 2021
}

Family violence has been among the most multifaceted phenomena across countries and regions (Tang \& Lai, 2008). China, a conventionally male-dominated society, is no exception. Starting from the late 1970s, China implemented the Open Door economic policy. Accompanying the rapid economic growth since then, women's social status has gained significant improvements. For example, the Fourth World Conference on Women was held in Bejing, the capital city of China, in 1995. The Conference passed a declaration to empower women and to advance gender equality. Women nowadays are believed to be able to hold up colloquially "half of the sky." Nevertheless, family violence in greater China remains an understudied area of research.

In mainland China, for instance, the All China Women's Federation (2011) revealed in 2011 that approximately one quarter of married women had experienced family violence of various kinds. The first Anti-domestic Violence Law (hereafter called the Law) that specifically deals with family violence, however, was not passed until December 2015. The Law officially came into effect on March 1, 2016. Although the Law marks a significant milestone for protection of victims in family violence, its effects remain unknown.

A recently published report on court cases concerning family violence in Beijing city reveals a total of 320 court verdicts (including civil, criminal, and administrative cases) between March 1, 2016 and the end of February, 2021. There was an average of only 64 verdicts per year. The number

Ruohui Zhao

rzhao@um.edu.mo

Shih-Ya Kuo

sykuo@um.edu.mo

Hongwei Zhang

hongwei_zhang888@hotmail.com

1 University of Macau, Avenida da Universidade, Taipa, Macau, China

2 Jinan University, 206 Qianshan Road, Zhuhai, Guangdong, China of verdicts reached $200(62.5 \%)$ in 2016, the year that the Law came into effect. It then dropped dramatically to less than 60 cases per year starting in 2017. There was only one verdict during the COVID-19 pandemic in 2020 (Beijing Yuanzhong Family \& Community Development Service Center, 2021).

Nationwide court statistics reveal similar findings suggesting that family violence has not been given enough attention by the Chinese criminal justice system. Between 2014 and 2016, Chinese courts of various levels reported having handled 94,571 first-instance divorce cases claiming to involve family violence. Notably, only 3,741 (3.96\%) cases were later affirmed to have involved family violence (Wei, 2017).

As with court case statistics, empirical research on family violence published in the Chinese language is also limited. While Chinese scholars paid increasing attention to family violence in 2016, this attention quickly faded (Zhang et al., 2019). A recently published scoping review on intimate partner violence (IPV) used "intimate partner violence," "family violence," "spousal violence," and "marital violence" as keywords to search all published empirical and quantitative journal articles in Chinese. This search resulted in only 68 articles published between 1982 and 2018 (Zhang et al., 2019), with increasing numbers of studies published in the last two decades. According to Zhang et al. (2019), most of these studies were not rigorously designed. Moreover, the published studies mainly reported on univariate descriptive statistics and bivariate comparisons of group means. Despite a rise in the number of studies published in Chinese, overall, the findings from this recent scoping review suggest that empirical research on family and intimate partner violence remains limited in both range and depth.

Different results have been found, however, among relevant articles published in internationally-recognized academic journals in English. The guest editors conducted a preliminary article search using "family violence" and "China" as keywords (for topics) in the Web of Science Core 
Collection database, a curated collection of peer-reviewed and high-quality scholarly publications worldwide (Clarivate, 2021). It found that as of the beginning of April, 2021, there was a total of 27 publications (including 24 journal articles) between 2000 and 2021. Although the number of publications is rather small each year, it continues to rise in recent years. Comparatively, when using "family violence" and "United States" as keywords, the search returned many more publications $(n=202)$ including 179 journal articles published between 1992 and 2021. The top three categories that publish family violence research in both China and the United States are family studies, social work, and criminology and penology. To ensure the validity of these findings, the guest editors then conducted a similar search in Scopus, a comprehensive, curated abstract and citation database with enriched data and linked scholarly content (Elsevier, 2021). This literature search revealed a similar pattern; there were notably more publications on family violence in the US than China (see Table 1).

Although this preliminary international academic database search is by no means exhaustive, it nevertheless suggests that few Chinese studies on this topic have reached an international audience. Indeed, China needs to produce more rigorously conducted empirical research to gain a comprehensive understanding of the nature, extent, causes, and consequences of family violence and the policies and programs related to it.

For this reason, we proposed this special issue calling for scholarly empirical studies about family violence in the greater China regions. The Journal of Family Violence, as an international and leading academic journal in family studies with an extensive readership, provides such a platform for Chinese studies to reach international audiences. This special issue includes nine research articles covering primarily two areas of family violence research in China: family violence against women and child maltreatment.

We first present the set of five articles reporting on family violence against women. While many previous studies have explored individual factors related to domestic violence, the first article of this set aims to address the impact of contextual factors on domestic violence. The next three articles focus on how female victims cope with family/domestic violence and exhibit help-seeking behavior. Lastly, the fifth article deals with police responses to domestic violence.

In the article "Cultural or Institutional? Contextual Effects on Domestic Violence against Women in Rural China," Song et al. (2021) investigate the relationship between cultural and institutional factors and risks related to domestic violence against women. They use a nationally representative sample of married women living in rural communities of mainland China. The findings show that the risk of domestic violence against women is associated with factors related to both culture (e.g., married women's inheritance rights) and institutions (e.g., information campaigns on the Law on the Protection of Rights and Interest of Women). These findings highlight the importance of changing patriarchal norms and promoting gender equality to combat domestic violence in rural China.

In the article "Trapped and Resistant Body: Everyday Practices of Women in Taiwan in the Context of Intimate Partner Violence," Zhang et al. (2021) use de Certeau's The Practice of Everyday Life (1984) as their framework for investigating experiences of abused women inflicted by IPV in Taiwan. They also focus on how these women survived their experiences with abuse. De Certeau argues that in a highly hierarchical society, those who hold resources and power create strategies (i.e., regulations and rules) to manage (or control) those who have few or no resources. However, those who have few or no resources may nonetheless implicitly find moments to escape such oppressive strategies using tactics to escape the influence of people who employ coercing strategies to control them. This study addresses two research questions. First, how did male offenders and other family members, friends, and agencies use strategies to interfere with abused women's lives and well-being? Second, how did abused women resist various forces of oppressions

Table 1 Comparing the numbers of family violence studies in China and the United States published in English-language journals between 2000 and 2021

\section{China United States Top Three Publication Categories}

Web of Science

Topic search using "family violence" and "China" or "United States" as keywords

\section{Scopus}

Publication title, abstract, and keyword search using "family violence" and "China" or "United States" as keywords

\begin{tabular}{|c|c|c|c|}
\hline Total no. of documents & 27 & 202 & \multirow{3}{*}{$\begin{array}{l}\text { Family studies, social work, and crimi- } \\
\text { nology and penology }\end{array}$} \\
\hline Total no. of journal articles & 24 & 179 & \\
\hline Range of years of publications & 2000-2021 & 1980-2021 & \\
\hline Total no. of documents & 50 & 926 & \multirow{3}{*}{$\begin{array}{l}\text { Medicine, psychology, and social sci- } \\
\text { ences }\end{array}$} \\
\hline Total no. of journal articles & 39 & 658 & \\
\hline Range of years of publications & $1985-2021$ & 1977-2021 & \\
\hline
\end{tabular}

Note: Results as of April 6, 2021 
by using subtle tactics to live their daily lives? The data used for this study comes from a large-scale study involving interviews with twenty-four abused women. These women were referred to one of the authors through three nonprofit women's services in Taiwan. The findings reveal that male abusers, in-laws, and friends either restricted abused women's movements in both home and public spaces or normalized violence to make abused women hesitate about seeking help. The modern institutions, including police and social services, provided initially helpful services to abused women, but the services were limited due to shortage of resources. These data also indicate that abused women fight against coercive strategies through the following relatively implicit tactics: sharing stories with their social media network, recording abusive evidence on a laptop, or staying at a public place with comforting air condition to be away from home as much as possible.

In the article entitled "The Patterns and Influencing Factors of Help-Seeking Decisions among Women Survivors of Intimate Partner Violence in China," Hu et al. (2021) address three research questions. First, what are the factors that affected abused women's decisions on whether seek help? Second, what are the behavioral patterns among the abused women who sought help for IPV? Lastly, what are the reasons for not seeking help among the abused women who did not seek help for the violence in their lives? The data used for the current study came from a 2015 survey study of 3,334 Chinese respondents. The authors recruited potential participants in different ways, such as sending invitations on Weibo and WeChat and collaborating with women's services in Beijing to distribute the survey to members and clients. The authors also recruited subscribers of specific groups focused on domestic violence in China. The final sample included 488 women who experienced at least one form of IPV. The results show that $73.4 \%$ of the participants did not seek any help. Among those who sought help, $86 \%$ sought help from friends and family members. The significant factor that contributed to seeking help was the termination of the relationship. In other words, women who had ended their relationship with abusive partners were more likely to seek extensive sources of help than the women who still had the relationship with their abusive partners. Abused women sought help mostly from their family and friends, rather than professional services. The common answers for not seeking help were: the victims felt they were able to handle the violence on their own, they did not know whom to ask for help, and they believed that their victimization experience was not severe.

In the qualitative article "Beyond 'Safeguarding' and 'Empowerment' in Hong Kong: Towards a Relational Model for Supporting Women Who Have Left their Abusive Partners," Kong (2021) explores the needs of women who experienced IPV after they had left their abusive male partners. Kong employs a novel research method involving collaboration between social work practitioner-researchers and women who experienced IPV to design, identify, and evaluate the needs of these women. The author invited seven Hong Kong Chinese women to meet six hours weekly for six months. These meetings involved reflection-action-reflection processes to guide the participants to identify challenges faced after leaving an abusive relationship. Throughout the process, the researcher and the abused women developed an alternative model called a relational model, which transcends "safeguarding" and "empowerment" models. Safeguarding emphasizes that abused women are helpless and vulnerable victims, while the empowerment model treats women as powerful and resilient survivors. The relational model, however, focuses on power sharing to incorporate the experiences of others in their understanding of IPV and are able to use their voice within a supportive community of women who have experienced IPV.

Lastly, in the article "Police Officers' Preferences for Gender-Based Responding to Domestic Violence in China," Wang et al. (2021) address two goals. The first is to investigate whether police officers perceive a specific gender of police officers, or a combination of genders, more suitable for dealing with domestic violence. The second goal is to identify the factors contributing to police officers' gender preferences when dealing with the three types of dependent variables (battered women, offenders, and domestic violence overall). The authors utilized survey questionnaires to collect data from 1,052 police officers in four Chinese provinces. The results demonstrate that female officers were considered most suitable for dealing with battered women, while male officers were considered most suitable for domestic violence perpetrators (predominately males), and a combination of both sexes was most suitable for handling domestic violence cases overall. The contributing factor that consistently explains the gender preference was the tolerance for domestic violence. In other words, participants who had high levels of domestic violence tolerance tended to favor female officers or a combination of both sexes to handle battered women, offenders, and domestic violence cases. The authors further explain that participants with relatively high levels of domestic violence tolerance might view domestic violence as "low priority," meaning that male officers should be reserved and assigned to more "serious" crimes.

The second set of four articles addresses the impacts of child maltreatment on either psychological or behavioral adjustment among both adolescent and adult samples. Two of the four studies focus on adolescents (including adolescents in general and adolescent offenders), while two studies focus on the childhood maltreatment experiences of adults.

The first study with a large student sample shows that child maltreatment is prevalent. In the article "A Path Analysis Investigating the Relationships between Family Violence, 
Addictive Behaviors, and Trauma among Adolescents in China," Li et al. (2021) use a large representative sample of adolescents in mainland China to explore the prevalence and effect of family violence on adolescents' addictive behaviors. The study has found that more than two-thirds of the sample either experienced child abuse or witnessed IPV engaged by their parent(s). In this study, family violence has a significant impact on adolescents' psychological (trauma symptoms) and behavioral (addictive behaviors) adjustment. Additionally, there is a potential reciprocal relationship between trauma symptoms and addictive behaviors, such as substance misuse and gambling.

In contrast, the second article, entitled "Child Maltreatment and Adjustment to Confinement: An Exploratory Study of Male Juvenile Offenders in China," explores the impact of child maltreatment on adjustment to confinement among a male juvenile offender sample (Zhao, 2021). This study found significant correlations between childhood maltreatment experiences and juveniles' adjustment to confinement. Specifically, childhood emotional abuse tended to increase adolescents' level of negative emotions while incarcerated. Moreover, childhood emotional neglect tended to increase the difficulty of adolescents' adjustment to prison life. Lastly, there was a positive correlation between childhood sexual abuse experiences and juvenile offenders' adjustment to prison life. These findings highlight the importance of offering institutional programs that assist juvenile offenders with childhood maltreatment.

The next two studies explored attitudinal and behavioral adjustment to child maltreatment among adult samples. In the article "Prevalence of Child Maltreatment and the Effects of the Intergenerational Transmission of Violence on Attitudes towards Domestic Violence in Chinese Police Cadets," Hayes et al. (2021) explore the prevalence of child maltreatment and attitudes toward domestic violence among a sample of police cadets. These cadets are future police officers who will handle family violence cases. The study determined that although the majority of the cadets experienced some form of child maltreatment, there was no statistically significant relationship between child maltreatment or witnessing domestic violence and police cadets' attitudes toward domestic violence. The study has also found that male cadets held more supportive attitudes toward domestic violence than female cadets. These findings highlight the importance of studying family violence in different cultural contexts. This work implies that some concepts and theories applicable in Western countries may not apply well to the Chinese context.

The final article concerning child maltreatment among an adult sample is Chen and Chu (2021) "The Link between Childhood Maltreatment, Prostitution, and Victimization of Physical Intimate Partner Violence: and Examination of Female Inmates in Taiwan." This article examines the direct relationship between childhood maltreatment and victimization of IPV. Moreover, this article investigates whether low self-control, risky lifestyles, and prostitution acted as mediating variables between childhood maltreatment and IPV. The data used for the study came from a larger survey study sponsored by the Ministry of Justice in Taiwan. The sample in the large study included 883 female inmates incarcerated in thirteen prisons. The authors adapted path analysis using LISREL 8.80 program with weighted least squares to analyze the quantitative data. The results show that there was no direct relationship between childhood maltreatment and IPV victimization, which was an unexpected finding. Among the incarcerated female sample, those who experienced maltreatment in childhood were most likely to have low self-control, engage in risky lifestyles and prostitution, and to become IPV victims. These results, on the other hand, aligns with that of prior research studies.

Taken together, the two sets of articles seek to provide a comprehensive understanding of family violence in greater China regions. These articles particularly focus on the prevalence, causes, and consequences of family violence against women and children as well as victim support services. All studies are empirically based and most represent close collaboration either among teams of Chinese scholars or between teams of Chinese and Western scholars.

Despite the existence of some consistent findings with Western studies, these nine studies highlight the unique culture of Chinese societies and call for greater incorporation of cultural factors in the study of family violence. As guest editors, we thank all the authors for their important contributions and hope this special issue can provide international readers with new insights into the study of family violence in China. We also hope that this issue results in additional empirical research on the topic in the future.

The Journal of Family Violence provides an international and professional platform for academic exchanges on family violence. We thank the journal's editorial team for their professional way of handling all the manuscript submissions of this special issue. We would like to extend our most sincere gratitude to the editor-in-chief, Professor Rebecca Macy, for all the support and advice given to the special issue on family violence in greater China. We would never have been able to make this special issue happen without her full support.

\section{References}

All China Women's Federation. (2011). Executive report of the 3rd survey on the status of Chinese women. Collection of Women's Studies, 6, 5-15. In Chinese.

Beijing Yuanzhong Family and Community Development Service Center. (2021). Judicial big data analysis report on family 
violence cases in Beijing city. Retrieved from http://download. caixin.com/upload/fjtblfbg.pdf?crazycache $=1$. In Chinese

Chen, Y. S., \& Chu, D. C. (2021). The link between childhood maltreatment, prostitution, and violent victimization of intimate partner: An examination of female inmates in Taiwan. Journal of Family Violence. https://doi.org/10.1007/s10896-020-00195-9

Clarivate. (2021). Web of Science Core Collection: A trusted, high quality collection of journals, books, and conference proceedings. Retrieved from https://clarivate.com/webofsciencegroup/ solutions/web-of-science-core-collection/.

Elsevier. (2021). Scopus: Expertly curated abstract \& citation. Retrieved from https://www.elsevier.com/solutions/scopus? dgcid=RN_AGCM_Sourced_300005030.

Hayes, B. E., Connolly, E. J., Wang, X., Ingham, C., \& Mason, M. (2021). Prevalence of child maltreatment and the effects of the intergenerational transmission of violence on attitudes towards domestic violence in Chinese police cadets. Journal of Family Violence. https://doi.org/10.1007/s10896-020-00182-0

Hu, R., Xue, J., Lin, K., Sun, I. Y., Wu, Y., \& Wang, X. (2021). The patterns and influencing factors of help-seeking decisions among women survivors of intimate partner violence in China. Journal of Family Violence. https://doi.org/10.1007/s10896-020-00145-5

Kong, S. T. (2021). Beyond 'safeguarding' and 'empowerment': Towards a relational model for supporting separated abused women in Hong Kong. Journal of Family Violence. https://doi. org/10.1007/s10896-020-00185-X

Li, W., O’Brien, J. E., Zhu, Y., \& Chen, Q. (2021). A path analysis investigating the relationships between family violence, addictive behaviors, and trauma among adolescents in China. Journal of Family Violence. https://doi.org/10.1007/s10896-020-00179-9

Song, Y., Zhang, J., \& Zhang, X. (2021). Cultural or institutional? Contextual effects on domestic violence against women in rural
China. Journal of Family Violence. https://doi.org/10.1007/ s10896-020-00198-6

Tang, S. C., \& Lai, B. P. (2008). A review of empirical literature on the prevalence and risk markers of male-on-female intimate partner violence in contemporary China, 1987-2006. Aggression and Violent Behavior, 13, 10-28. https://doi.org/10.1016/j.avb.2007. 06.001

Wang, X., Wu, Y., Li, L., \& Xue, J. (2021). Police officers' preferences for gender-based responding to domestic violence in China. Journal of Family Violence. https://doi.org/10.1007/ s10896-020-00237-2

Wei, L. (2017). 100,000 divorce judgments nationwide tell you a few secrets of family violence. Retrieved on July 2, 2018, from http:// news.youth.cn/sh/201705/t20170507_9687976.htm. In Chinese

Zhang, H., Zhao, R., Macy, R. J., Wretman, C. J., \& Jiang, Y. (2019). A scoping review of 37 years of intimate partner violence research in China. Trauma Violence Abuse. https://doi.org/10.1177/15248 38019881738

Zhang, L., Kuo, S. Y., \& Simpson, T. (2021). A trapped and resistant body: The everyday practices of women in Taiwan in the context of intimate partner violence. Journal of Family Violence. https:// doi.org/10.1007/s10896-020-00192-y

Zhao, R. (2021). Child maltreatment and adjustment to confinement: An exploratory study of male juvenile offenders in china. Journal of Family Violence. https://doi.org/10.1007/s10896-020-00191-z

Publisher's Note Springer Nature remains neutral with regard to jurisdictional claims in published maps and institutional affiliations. 